\title{
Common Elements Treatment Approach based on a Cognitive Behavioral Intervention: implementation in the Colombian Pacific
}

\author{
Abordagem de Tratamento de Elementos Comuns \\ com base em uma Terapia Cognitiva de Conduta: \\ realização no Pacífico Colombiano
}

\author{
Sara Gabriela Pacichana-Quinayáz ${ }^{1}$ \\ Gisel Viviana Osorio-Cuéllar ${ }^{1}$ \\ Francisco Javier Bonilla-Escobar ${ }^{1}$ \\ Andrés Fandiño-Losada ${ }^{1}$ \\ María Isabel Gutiérrez-Martínez ${ }^{1}$
}

${ }^{1}$ CISALVA Institute, Universidad del Valle. Calle 4B\#36-00/Building 100/Office 114. Cali Colombia.sara.pacichana@ correounivalle.edu.co

\begin{abstract}
Due to the limited supply of mental health services for Afro-Colombian victims of violence, a Common Elements Treatment Approach (CETA) intervention has been implemented in the Colombian Pacific. Given the importance of improvement in mental health interventions for this population, it is necessary to characterize this process. This article seeks to describe the implementation of CETA for Afro-Colombian victims of violence in Buenaventura and Quibdó, Colombia through case studieswith individual in-depth interviews with Lay Psychosocial Community Workers (LPCW), supervisors, and coordinators responsible for implementing CETA. From this six core categories were obtained: 1. Effect of armed conflict and poverty 2. Trauma severity 3. Perceived changes with CETA 4. Characteristics and $L P C W$ 's performance 5. Afro-Colombian culturalapproach and 6. Strategies to promote users' well-being.Colombian Pacific's scenario implies several factors, such as the active armed conflict, economic crisis, and lack of mental health care resources, affecting the implementation process and the intervention effects. This implies the need to establish and strengthen partnerships between institutions in order to administer necessary mental health care for victims of violence in the Colombian Pacific.
\end{abstract}

Key words Mental health, Violence, Community mental health services, Cognitive therapy
Resumo Devido à carência de serviços em saúde mental destinados aos Afro-colombianos vítimas de violência, a intervenção CETA (Common Elements Treatment Approach) foi implementada no pacífico da Colômbia. Dada a importância em melhorar essas intervenções, é necessário caracterizar o seu processo de execução. O objetivo deste artigo é descrever a realização da intervenção CETA para Afro-colombianos vítimas de violência em Buenaventura e Quibdó, Colômbia. Trata-se de estudo de caso com elaboração de entrevistas aprofundadas a Trabalhadores Comunitários Psicossociais (TCP), supervisores e coordenadores responsáveis pela execução CETA. Obtiveram-se seis categorias Núcleo: 1. Efeito do conflito armado e pobreza; 2. Severidade do trauma; 3. Mudanças percebidas com a intervenção CETA; 4. Características e desempenho dos TCP; 5. Enfoque na cultura Afro-colombiana; e 6. Estratégias para promover bem estar dos usuários. O contexto do pacífico colombiano está relacionado a múltiplos fatores, como o conflito armado ativo, crise econômica, e carência de serviços em saúde mental, afetando o processo de implementação e seus efeitos. Isto gera a necessidade de fortalecimento e estabelecimento de alianças institucionais, visando garantir a saúde mental das vítimas dessa região. Palavras chave Saúde mental, Violência, Serviços comunitários de saúde mental, Terapia cognitiva 


\section{Introduction}

Colombia is experiencing an armed conflict that affects mainly rural communities. Pacific region is a strategic area for the settlement of armed groups which dispute the natural resources and the control of drug traffic bussines due to the maritime border.These armed groups have committed human rights violations, causing massacres and massive displacement of people to the two largest municipalities in the region: Bue-

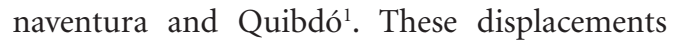
are mainly affecting the Afro-Colombian population ${ }^{2}$.

This population is one of the most affected by social segregation, racial discrimination, government neglect and abandonment of the state, that is, impoverished conditions ${ }^{3,4}$. Due to internal armed conflict, in 2013, 33,058 displaced people were reported and 22,330 people were received in Buenaventura, and 2,340 displaced people were displaced and 1,389 people were received in Quibdó ${ }^{5}$.

In response to the needs of victims, in 2011, Heartland Alliance International (HAI) in partnership with the Johns Hopkins University (JHU), the National Association of Displaced Afro-Colombians (AFRODES) and the Cisalva Institute of Universidad del Valle, Colombia, implemented the programACOPLE (in Spanish: Asociacion de Organizacionespor lo Emocional), in order to offer a community-based therapy for victims ofviolence in the Colombian Pacific region.

Additionally as part of the ACOPLE program, the Cisalva institute implemented the "Evaluation of two Community-based Interventions in Mental Health, for the Afro-Colombian Victims of Violence in Buenaventura and Quibdó, Colombia" a study for assessing the effectiveness of two therapiesintended to decrease mental health symptoms of Afro-Colombian victims of violence compared to a waiting/control group. One intervention arm was the individual Common Elements Treatment Approach (CETA), based on cognitive-behavioral therapies, and the other was the Narrative Community-based Group Therapy (NCGT), based on narrative therapies ${ }^{6,7}$.

CETAwas a therapy designed for settings with scarce mental health care coverage in Low- and Middle-Income Countries ${ }^{8}$, demonstrating effectiveness in reducing post-traumaticstress disorder (PTSD) symptoms ${ }^{9}$, Given the lack of facilities and specialized mental health professionals in those settings, community leaders or local lay counselorsin each community can instead learn and apply this therapy ${ }^{8}$. After the intervention was adapted to the Colombian context by experts of JHU, HAI and Cisalva, Lay Psychosocial Community Workers (LPCWs) were trainedin delivering this technique and they were constantly supervised by mental health professionals (psychologists and social workers) throughout the project ${ }^{7}$.

To our knowledge, this is the first intervention using the trans-diagnostic approach in the Colombian Pacific region and it is also the first community-based mental health intervention in active conflict settings in Latin-America ${ }^{7}$; thus, it is necessary to characterize its implementation process. Given the importance and usefulness of analyzing social interventions from the perspective of involved staff ${ }^{10,11}$. This study describes the CETA implementation process, based on perceptions of the therapy implementers (LPCWs) in Buenaventura and Quibdó, Colombia. Thus, the study aim is to scrutinize this type of intervention in order to improve the implementation process of future community-based programs in limited resource setting ${ }^{12,13}$.

\section{Methodology}

\section{Design and study population}

A case study of CETA implementation was conducted through individual in-depth interviews with ACOPLE staff (LPCWs, supervisors and coordinators) responsible for implementing and monitoring therapy in Buenaventura and Quibdó, Colombia, between 2011 and 2013. Included participants were those with availability during the study period and who voluntarily agreed to participate.

Sampling was done for convenience. Three from five LCPWs and a coordinator were included in Quibdo, and two from 4 LCPWs and a coordinator in Buenaventura. Furthermore, the supervisor and the HAI Coordinator, common to both cities, also participated for a total of nine people.

\section{Procedures}

Two models by the World Health Organization (WHO) were consulted for the construction of inquiry lines: the ecological theoretical model of the violence and the vicious cycle model of social determinants and mental disorders ${ }^{14,15}$. From 
these, three inquiry lines were proposed: 1) Presence of limits or barriers totherapy participation/ performance; 2) Perception of intervention effectiveness; and 3) Future applications and recommendations.

Two pilot tests were performed with subjects differing from the study sample but with similar profiles to the expected population. Thus, a cognitive interview strategy was applied to make adjustments to the guiding questions ${ }^{16}$.

\section{Data collection}

Data were collected between June and August 2014 through individual in-depth interviews lasting 30-60 minutes with two meetings scheduled per person. Two days were spent for interviews with each ACOPLE care center. In Quibdó, interviews were conducted personally; in Buenaventura, they were performed by video-call as a result of security issues. During the interviews, clear and simple language was utilizedfor assuring simplicity and assertiveness by respondents.

Confidentiality and anonymity of information were maintained through a coding system. The interviews were conducted in safe and quiet environments that promoted trust and responsiveness. Verbal consent was obtained from all participants. The saturation of information was the limit for determining the number of interviews per person and the sample size.

\section{Data Analysis}

After data triangulation, a narrative content analysis was performed using Open Code Software Version $5.0^{\circledR}$. Accordingly, core categories were identified and named, through a process of verification and confirmation, allowing for different perspectives until category saturationwasobtained.Data analysis involved two analysts whoensured the reduction of interpretation bias ${ }^{10}$; additionally, peer validation guaranteed the rigor of the analysis process ${ }^{17}$.

This study is part of the research "Evaluation of two Interventions in Mental Health, Community Based, for the Afro-Colombian Victim of Violence in Buenaventura and Quibdó, Colombia”, approved by the Institutional Board Review of Human Ethics of Universidad del Valle, Colombia, with internal code No. 014-011. Specifically, for this paper, no contact was carried out with the participants of the randomized control trials $s^{6,7}$.

\section{Results}

Six core categories emerged from interviewees' perceptions:1) Effects of armed conflict and poverty, 2) Trauma severity, 3) Perceived changes with CETA intervention, 4) Characteristics of LPCWs and their performance, 5) Afro-Colombian cultural approach, and 6) Strategies to promote users' wellbeing (See Figure 1. Results core categories Diagram).

\section{Effects of armed conflict and poverty}

There is a resurgence of violence in Buenaventura, and to a lesser extent in Quibdó, as manifested by respondents. These events continue to be stressful factors that cause mental health symptoms in this population, generating uncertainty about whetherintervention effects were maintained in time or if it could have a setback as a result of that.

These two years we were in therapy and cut energy in the city, pulling tower energy, people had to be enclosed in neighborhoods, there were threatening statements in streets [...], although you'll heal them they living in a city so overwhelmed by armed conflict, soif patients have an improvement we cannot know how much they will last because the exposure to conflict.

Also, due to structural poverty in these municipalities, the consequences of being a victim intensify with the emergence and / or worsening of unsatisfied basic needs, such as improper conditions for human accommodation, inadequate sanitation, and high economic dependence.

Those who suffered displacement, which lost everything and here live in houses borrowed, rented and do not have money for paying [...] say: <look, I had my farm, I had it all, and I lost everything, now I live resigned but I will never forget that, that keeps me a little heartbroken $>$.

Respondents considered these factors affecting attendance therapies, as some users expressed lack of financial resources to obtain food, being unemployed, and living in an informal economy; these provided reasons whytheycould not refuse to work when they had the opportunity. However, the ACOPLE team tried to adapt therapy schedules when itinterferedwith a participant's job.

I also think that people have other priorities, sometimes for example, in economic sphere, if you are hungry, mental health will be secondary, or if you get a job for your family maintenance, during a short week, then you will prioritize that. 


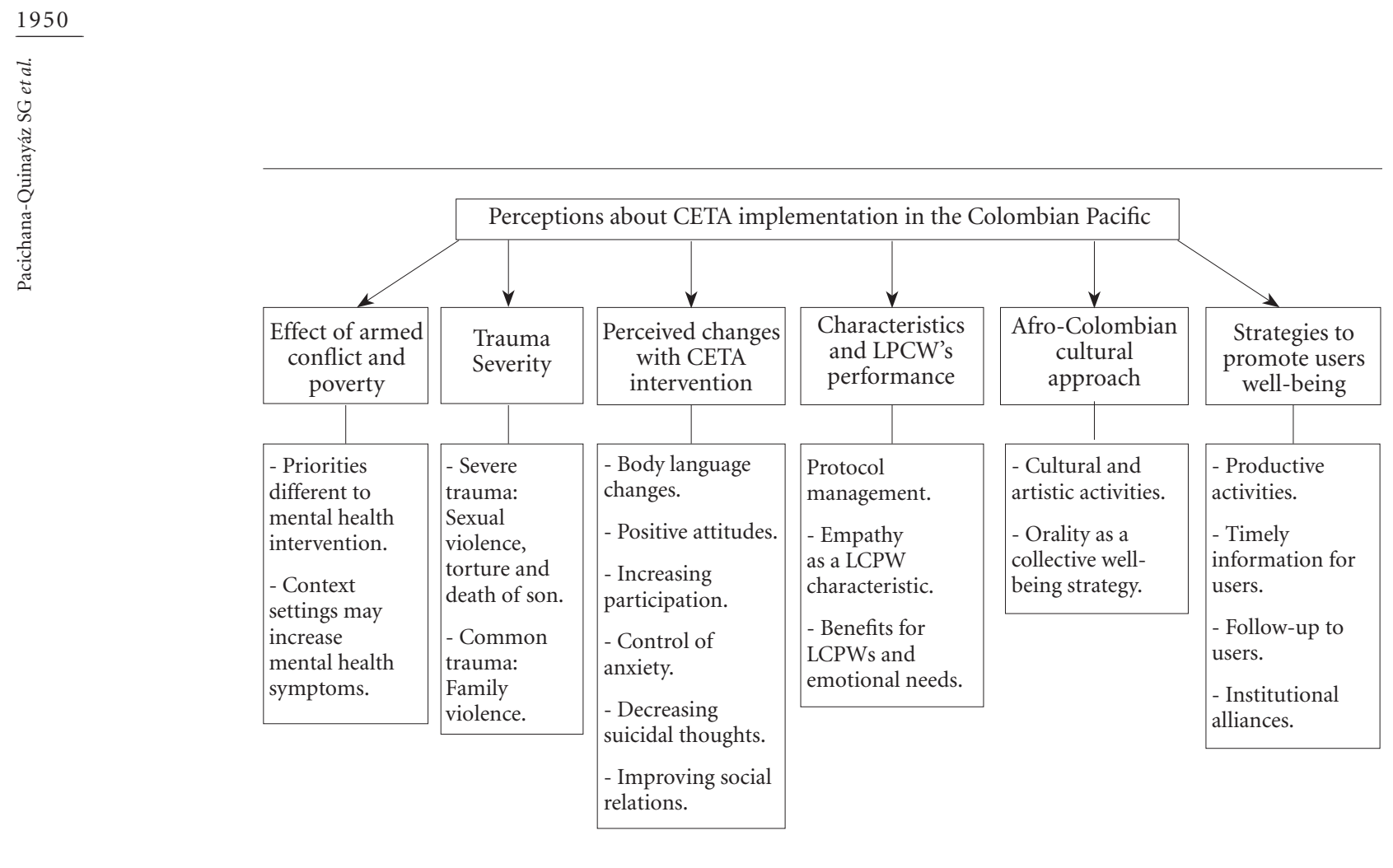

Figure 1. Results core categories diagram.

\section{Trauma Severity}

Some LPCWs consider that traumas and theirseverity are different in each person, including their ways of coping which could indicate the need for differential treatment in mental health. These are exemplified as severe trauma, those related to the murder of a son, sexual violence or torture.

Type of trauma had a better or worse prognosis, for example, those people with situations of torture or sexual violence had a much slower recovery, [...] if causing depression or anxiety was violence sexual, was much stronger and overcome symptoms.

As for domestic violence, it is regarded as a problem of low complexity, unlike the traumas associated with displacement and torture. This is because communities perceive the issue of family violence as a common problem and it is considered easier for the victim to live and deal with it.

cases of domestic abuse [...] that were happening recently, also in the environment that we live in some ways is common, then it is as easy face it instead of a person who's been raped or tortured during displacement.

\section{Perceived changes with CETA intervention}

Interviewees noted early changes in users. Since the first three sessions, less anxiety, more expression and confidence, better face, feeling better about the future, a greater understanding of the therapy, and concentration as a result of thatwere all appreciated. According to testimony, users acknowledge the opportunity to talk about their traumas as being an emotional release, particularly with the accompaniment of a counselor and a psychologist.

I worked with a raped victim very young, so first day she came was terrible, overflowed emotionally and cried a lot, she said: $<$ I never talk about this with anyone, this is killing me and I know what will happen to me if I do not talk > [...] It is easier than after downloading it to carry inside for many years because their fear to talk about it, when these people dare, recovery it is easier.

They also recognized in users a better ability to handle some anxiety symptoms and implement strategies learned. In the users' words, these techniques provided them with satisfaction since they were able to anticipate symptoms or a severe anxiety response to an episode.

So when you started work history and did relaxation techniques, we always remember to them measure their levels of anxiety and fear at 
home, and always told us: $<$ I feel good since I'm talking $><$ This really works $>$.

Another notable change is an improvement in interpersonal relationships. Some LPCWs mention that changes in family dynamics and generating a conciliatory atmosphere between parents and sons in some users were both possibly due to a decrease in feelings of anger and sadness. Moreover, reducing fears allowed them to go out of their homes and frequent community environments that were avoided before, allowing for the establishment of relations with neighbors and family once again.

They tell: < Scares me go where my neighbor, talk with my relatives $>$, then they were slowly go out their homes [...] as time passed, they were saying felt much better and could perform such activities.

Most respondents believed that intervention reduced stigma in mental health issues; this reduced stigma was not only observed in therapy users but also in the LPCWs. Also, it was identified that users recognizedthe benefits of therapy and sometimes expressed a desire to extend this service rather thanothers, which is consistent with an open attitude toward this type of intervention, making the community more active in seeking these services.

I initially thought that therapy was for crazy ones, but not anymore [...] in sessions they said: $<I$ used to think it was for crazy ones, but really we need this service because displacement consequences>

People who really change beginning to help others, or newer, which came after therapy, they begin to teach what they learned [...] we valued when they started making support networks with its neighbors and the institutions too.

\section{Characteristics and LPCWs performance}

Both municipalities referred to the flexibility of therapy or stiffness of it as a positive andnegative factor, respectively. Some individuals admitted that the therapy was stiff but allowed for its implementation; others considered it difficult to adapt to an individual's needs. In contrast, some felt that the therapy was flexible as they could devote more sessions to a particular component if users so desired.

All patients are different [...] if I start from first component until the sixth, possibly in that order works for you but will not work for another one.

Respondents mentioned an important point within the CETA intervention: In a first contact,
LPCW must make an effective "hook" which allows one to determine if participants are interested in attending therapy. Supervisors believe that LPCW should have communication skills, be resourceful, flexible and have enough creativity to conduct therapy. Many agreed that LPCW empathy was one of the main strengths, developed because of their traumatic experiences.

Most of us are also displacement victims, then it is also very easy to understand, I think I know how to create empathy with people and that gives them confidence.

According to interviewees, there are some benefits for LPCW including the generation of income and relative economic stability, wellbeing, autonomy and mental health tools that strengthen the skills of individuals to develop their own work and extend the therapy benefits into their daily lives and family life.

Every day there was more motivation work because I understood how to manage that component of trauma. [...] Then, because these work, I could use knowledge daily and family life.

Moreover, being aware of the emotional risks involved with LPCW exposed to stories about violence, respondents recognized difficulties they might have to handle in thesedifficultsituations within therapies. However, they emphasized the supervisor support and the spaces where the team gathered for feedback as crucial for answering questions and allowing for emotional release.

During therapy they heard similar situations as they had to live [...], so I think they were quite strong themes. We had a space called $<$ Help the helper $>$; oxygenate is part of the team and able to talk to everyone about what it is overwhelming to me as a therapist.

\section{Afro-Colombian culture approach}

A point emphasized by interviewees refers to a participant approach and management of CETA intervention from a cultural perspective. Participants mentioned that the protocol language was technical and the LPCW's discursive ability to transmit a message to the participant was necessary so that they could understand each component. Other issues they mentioned that should be considered for intervention were the conservation and implementation of Afro-Colombian traditions related to artistic and cultural activities such as dancing, singing, food, fabric or any art that would allow them to take time and generate a vindication of person in order to feel useful. 
CETA intervention has a lack of cultural approach, lacks of getting into black community and maybe there are things we should be working $[. .$. there are rites, customs that we could recover and that could have a very healing effect on person.

The importance of community networks within the Afro-Colombian culture was also evident. Furthermore, how, through the intervention, the knowledge and strategies learned in therapy could provide tools for users to respond to similar situations of victimization within their community were also evident.

Therapy was confronting person with their feelings, [...] so if those situations repeated, or someone in the community suffered a similar situation now they know how to procedure, they would empower them, and then collaborated members of community because intervention ends but knowledge remains into community.

\section{Strategies to promote users' wellbeing}

Respondents recognized that therapy produces positive changes; however, they mentioned that these changes are adversely affected by factors such as poverty and violence in these municipalities. Therefore, it is important to consider the need for strategic alliances with institutions that can promote the generation of incomeand the recognition of each person and their right to education, health, and recreation, among others. Also, this highlights that users able to bring this kind information could generate a greater well-being.

There are many people who always talk about economic situation, then say: $<$ I have these problems because I do not have job $>$, sometimes we do not how answer to that [...] if we can bring some information that could benefit person, then it would help a little more.

Likewise, respondents stated that monitoring cases and contact with users once the intervention finished can promote their wellbeing since Afro-Colombian communities tend to generate ties and cultural feelings during these intervention processes.

\section{Discussion}

The socio-political panorama of Colombia's armed conflict persists and this continues to generate victims. Hence, ACOPLE implements two lay-provided community-based therapies to mitigate the scarcityof mental health services in the Colombian Pacific region. Thus, it is import- ant to understand the factors that affect the implementation of these therapies and specifically CETA in this article.

Some of these factors, such as poverty and armed conflict, act as daily stressors. It has been reported that barriers to access to basic health services, which is the situation in the Colombian Pacific region, compromises survivors' mental health ${ }^{18,19}$. These daily stressors are associated with sadness, depression, and anxiety ${ }^{19,20}$. Furthermore, these lead to poor recovery because permanent or increasing violence perpetuates a breakdown in social dynamics that hampers individual, family, and collective coping abilities. Therefore, promoting the reduction of these factors would contribute to decreased mental health symptoms and increased resilience ${ }^{20,21}$.

Regarding changes after the intervention, better management of anxiety and fears as well as a better attitude towards life was reported by users; this response promoted the strengthening of support networks between family and community. It was described how these changes contribute in restructuring relationships in family and community settings, bringing anattitude to help others, and the development of empathy and understanding ${ }^{21,22}$.Also, it was documented how listening to scenarios contributes to positive mental changes because they tackle the structural exclusion and isolation of victims of violence, addressing their need for sharing emotional symptoms ${ }^{18,23,24}$.

One of the main problems that ACOPLE users have faced was the stigmatization of psychosocial interventions. This has been associated with low utilization of mental health services, which delays victims' recovery ${ }^{18,23,25}$. Therefore, implementing psycho-education strategies offered by community members staff allows for areduction in stigmatizing attitudes in communities ${ }^{18,21,26}$. In this manner, psycho-education is the first component of CETA intervention.

Psycho-education strategies implemented in the CETA therapy allowed users to identify and anticipate anxiety symptoms. It has been shown that educating people about their symptoms and how they are associated with interpersonal difficulties allows them to manage anxiety and depression symptoms effectively. Furthermore, it has been reported that one of the key components of psycho-education is to provide timely information about socialwell-being organizations $^{27,28}$; interviewees emphasize the importance of these data, considering the psychosocial needs of each user. 
Regarding the LPCWs, positive findings havebeen reported regarding training such personnel on mental health issues due to the relatively low cost, greater availability and adequate effectiveness in assisting and accompanying people with mental disorders ${ }^{26,27,29}$. In addition, it has been shown that when training community lay-workers in mental health promotion and psychological illness prevention, the clinical supervision should be consistent, as was the case in this study. This issue involves reducing emotional risks and offering the personal and professional growth of LPCWs, which would increasemental health awareness in the general population ${ }^{26,29-31}$.

On the other hand, the need to integrate traditional and cultural knowledge of Afro-descendant populationsinto the CETA intervention was evident.Not only was the identification of local symptoms of mental health important ${ }^{7}$ but also the use of Afro-Colombian culturalwords and expressions to communicate the CETA therapy important as an element for facilitating its understanding. This helps to build the confidence of users and promotes empathic rapport and communication with the LPCWs ${ }^{13,30,31}$. Different studies highlight the importance of scientific rigor combined with the application of a differential approach that promotes the healing processes within communities ${ }^{18,20,21}$. It was even reported that traditional coping strategies, such as rites and prayers, are protective factors in post-conflict and complex political contexts ${ }^{28,32,33}$.

Likewise, psychosocial care for victims, as manifested by respondents, cannot occur in an isolated context. Therefore, other factors and requirements that promote recovery from mental disorders, such as satisfaction of basic needsand the reconstruction of support networks and empowerment ${ }^{34}$, need to be addressed in a coordinated way by national and international agencies, including partnerships for social welfare.

To our knowledge, this is the first study on perceptions about implementing a CETA intervention in the context of poverty and active armed conflict. Moreover, CETA is an adaptation of cognitive-behavioral therapies, whose effectiveness is supported by the Cochrane Collaboration Group'. Thus, findings from the study are an input for replication of mental health interventions, taking into account that previous studies are limited to post-conflict scenarios ${ }^{8,22,32}$.

On the other hand, the research findings cannot be generalized to cultural settings differingto that of the Afro-Colombians but they could guide mental health interventions in similar conflict contexts. Additionally, only the CETA intervention implementers were interviewed which could bias some findings regarding the implementation process. Thus, it is recommended that future research should include perceptions of treated individuals to investigate the intervention's effectsusing a qualitative approach.

In conclusion, this study explores the perceptions of CETA therapy implementers in the Colombian Pacific context. This scenario implies the existence of several factors, such as the active armed conflict, economic crisis, and lack of mental health care resources that affect the implementation process and the intervention effects. This implies the need to establish and strengthen partnerships between institutions of different sectors in order to promote the continuity of mental health care for victims of violence in the Pacific region of Colombia. 


\section{Collaborations}

SG Pacichana-Quinayáz worked on the study design, data collection, analysis and the drafting process of the article. GV Osorio-Cuellar participated in the study design and contributed to drafting the article. FJ Bonilla-Escobar and A Fandiño-Losada participated in the study design, supervised the research process, revised the article critically and approved the final version to be published. MI Gutierrez-Martinez participated in revising the article critically and approved the final version to be published.

\section{Acknowledgments}

To Administrative Department of Science, Technology and Innovation of Colombia - COLCIENCIAS. Authors thanks Eva Duarte and Diego Fernando Rodríguez Mendieta, Country Director (Colombia) and Clinic Director (Colombia) of Heartland Alliance International, for their collaboration during the interview process and for their feedback on the results. 


\section{References}

1. Carrillo A. Forced Displacement and Gender-based Sexual Violence. In: Norwegian Refugee Council NRC, Supported by the United Nations High Commissioner for Refugees, editors. Buenaventura, Colombia: Brutal realities. Bogota: NRC; 2014. p. 20.

2. United Nations Human Rights. Anual report of the United Nations High Commissioner for Human Rights. Bogotá: Office of the High Commissioner for Human Rights; 2014.

3. López-Viáfara CA. Informe Final de Derechos Humanos Movimiento Nacional Afrocolombiano. Bogotá: Movimiento Nacional Afrocolombiano; 2009.

4. Unión Temporal Alianza Progreso Afro. Plan nacional de desarrollo de comunidades negras, afrocolombianas, raizales y palenqueras 2010-2014: Hacia una colombia plurietnica y multicultural con prosperidad democrática. Bogotá: Unión Temporal Alianza Progreso Afro; 2014.

5. Colombian Goverment. Unidad para la atención y reparación integral a las víctimas. [cited $2015 \mathrm{Feb} 1]$. Available from: http://www.unidadvictimas.gov.co/

6. Bonilla FJ, Fandiño CA, Martinez D, Santaella J, Escobar I, Tobón D, Gutiérrez-Martínez MI.. Narrative Community-Based Group Therapy in Violence-Displaced Afro Colombians. A Randomized Controlled Trial. Cali: Instituto Cisalva, Universidad del Valle; 2015.

7. Bonilla FJ, Fandiño CA, Martínez DM, Santaella J, Tobón D, Muñoz EJ, Gutiérrez-Martínez MI. A Randomized Controlled Trial of a Transdiagnostic Cognitive-Behavioral Intervention for Afro-descendants Survivors of Systemic Violence in Colombia. Cali: Instituto Cisalva, Universidad del Valle; 2015.

8. Murray LK, Dorsey S, Haroz E, Lee C. A Common Elements Treatment Approach for Adult Mental Health Problems in Low- and Middle- Income Countries. Cogn Behav Pract 2014; 21(2):111-123.

9. Bisson JI, Roberts NP, Andrew M, Cooper R, Lewis C. Psychological therapies for chronic post-traumatic stress disorder (PTSD) in adults. The Cochrane database of systematic reviews 2013; 12:CD003388.

10. Cifuentes RM. Designing qualitative research projects]. [Designing qualitative research projects. Argentina: Noveduc; 2010. p. 313-316.

11. Green J, Thorogood N. Qualitative methods for health research. $3^{\text {rd }}$ ed. New York: Sage; 2013.

12. Getrich C, Heying S, Willging C, Waitzkin H. An ethnography of clinic "noise" in a community-based, promotora-centered mental health intervention. Soc Sci Med 2007; 65(2):319-330.

13. Pinto RM, da Silva SB, Soriano R. Community health workers in Brazil's Unified Health System: a framework of their praxis and contributions to patient health behaviors. Soc Sci Med 2012; 74(6):940-947.

14. World Health Organization (WHO). World report on violence and health. $3^{\text {rd }}$ ed. Geneva: WHO; 2002.

15. Blas E, Sivasankara Kurup A. Equity, social determinants and public health programmes. Geneva: World Health Organization; 2010.

16. Beatty P, Willis G. Research synthesis: The practice of cognitive interviewing. Public Opin Quart 2007; 71(2):287-311.

17. Creswell JW. Research design: Qualitative, quantitative, and mixed methods approaches. New York: Sage publications; 2013.
18. Rees $\mathrm{K}$, Zweigenthal V, Joyner K. Implementing intimate partner violence care in a rural sub-district of South Africa: a qualitative evaluation. Glob Health Action 2014; 7:24588.

19. Agudelo CE. The Pacific coast of Colombia: from "peaceful haven" to strategic cockpit of the armed conjlictl The transformations in the region and some responses to violence on the part of its inhabitants. Cuad Desarro Rural 2001; (46):7-37.

20. Mels C. Between poverty and violence: how do daily stressors and exposure to violence affect Adolescents living in a war zone? Cienc Psicol 2012; 6(2):111-122.

21. Connell J, O'Cathain A, Brazier J. Measuring quality of life in mental health: Are we asking the right questions? Soc Sci Med 2014; 120:12-20.

22. Murray KE, Davidson GR, Schweitzer RD. Review of refugee mental health interventions following resettlement: best practices and recommendations. Am J Orthopsychiat 2010; 80(4):576-585.

23. Acuña C, Bolis M. Stigma and access to health care in Latin America: Threats and Prospects. Paris: PAHO, WHO; 2005.

24. Mogollón AS, Vázquez M, García M. Health-Related Needs of the Displaced Population Due to Armed Conflict in Bogota. Rev Esp Salud Public 2003; 77(2):257266.

25. Armstrong G, Kermode M, Raja S, Suja S, Chandra P, Jorm AF. A mental health training program for community health workers in India: impact on knowledge and attitudes. Int J Ment Health Syst 2011; 5(1):17.

26. Murray LK, Tol W, Jordans M, Sabir G, Amin AM, Bolton P, Bass J, Bonilla-Escobar FJ, Thornicroft G. Dissemination and implementation of evidence based, mental health interventions in post conflict, low resource settings. Intervention 2014; 12(Supl. 1):94-112.

27. Patel V, Weiss HA, Chowdhary N, Naik S, Pednekar $S$, Chatterjee S, Effectiveness of an intervention led by lay health counsellors for depressive and anxiety disorders in primary care in Goa, India (MANAS): a cluster randomised controlled trial. Effectiveness of an intervention led by lay health counsellors for depressive and anxiety disorders in primary care in Goa, India (MANAS): a cluster randomised controlled trial. Lancet 2010; 376(9758):2086-2095.

28. Somasundaram D. Collective trauma in the Vanni-a qualitative inquiry into the mental health of the internally displaced due to the civil war in Sri Lanka. Int $J$ Ment Health Syst 2010; 4(22):1-31.

29. Ashwell HE. The clinical competency of community health workers in the eastern highlands province of Papua New Guinea. Papua New Guinea Med 1995; 38(3):198-207.

30. Mendenhall E, De-Silva M, Hanlon C, Petersen I, Shidhaye R, Jordans M, Luitel N, Ssebunnya J, Fekadu A, Patel V, Tomlinson M, Lund C. Acceptability and feasibility of using non-specialist health workers to deliver mental health care: Stakeholder perceptions from the PRIME district sites in Ethiopia, India, Nepal, South Africa, and Uganda. Soc Sci Med 2014; 118:33-42.

31. Satkunanayagam K, Tunariu A, Tribe R. A qualitative exploration of mental health professionals' experience of working with survivors of trauma in Sri Lanka. Int J Cult Ment Health 2010; 3(1):43-51. 
32. Somasundaram D, Sambasivamoorthy S. Rebuilding community resilience in a post-war context: developing insight and recommendations - a qualitative study in Northern Sri Lanka. Int J Ment Health Syst 2013; 7(1):1-25.

33. Bonilla FJ, Osorio G, Pacichana SG, Sanchez G, Fandiño CA, Gutierrez MI. Do not forget culture when implementing mental health interventions. Cali: Instituto Cisalva - Universidad del Valle; 2015.

34. Restrepo DA, Muñiz OA. Approach to the state of the art of research and experiences of psychosocial intervention in mental health in the field of violence in Colombia between 1999 and 2003. Informes Psicológicos 2005; (7):71-107.

Artigo apresentado em 27/04/2015

Aprovado em 22/08/2015

Versão final apresentada em 24/08/2015 